\title{
Estudo preliminar sobre a ocorrência de Leishmaniose visceral em seres humanos no município de Vassouras, RJ, Brasil
}

\author{
Preliminary study on the occurrence of visceral Leishmaniasis in humans in the municipality of Vas- \\ souras, RJ, Brazil
} Robson Vettore Nogueira Petrin*, João Pedro Maciel de Almeida e Silva, Gisele Euzébio de Faria, Caio
do Canto Mendonça, Walter Tavares, Flávia Clare Goulart de Carvalho

\begin{abstract}
Resumo
Procurou-se identificar a infecção humana por Leishmania chagasi em dois bairros da cidade de Vassouras, Estado do Rio de Janeiro, onde foram identificados cães infectados por esse parasito. Foi realizada sorologia por técnica de ELISA (Enzyme-Linked Immunosorbent Assay) em 17 pessoas que tiveram contato com cães infectados. A sorologia foi negativa em todas as amostras colhidas. Paralelamente, realizou-se trabalho educativo junto à população dos locais estudados, esclarecendo sobre medidas preventivas em relação ao calazar, enfermidade cuja descrição vem aumentando em municípios próximos a Vassouras.
\end{abstract} $\begin{array}{llll}\text { Como } & \text { citar esse artigo. Petrin } \\ \text { RVN, } & \text { Silva JPMA, Faria GE, }\end{array}$ Mendonça CC, Tavares W, Carvalho FCG. Estudo preliminar sobre a ocorrência de Leishmaniose visceral em seres humanos no município de Vassouras, RJ, Brasil. Revista de Saúde. 2016 Jan./Jun.; 07 (1): 04-10.

\begin{abstract}
Human Leishmania chagasi infection was investigated in two neighborhoods of the municipality of Vassouras, State of Rio de Janeiro, Brasil, where dogs infected by this parasite were identified. Serology was performed by ELISA (EnzymeLinked Immunosorbent Assay)test in 17 people who had contact with infected dogs. Serology was negative in all samples. At the same time, educational work was accomplished among the population of the studied sites about preventative measures in relation to visceral leishmaniasis, a disease whose description has been increasing in municipalities near Vassouras.
\end{abstract}

Keywords: Leishmaniasis, Visceral; Protozoan Infections; Epidemiology; Health Education.

\section{Introdução}

Leishmanioses são doenças causadas por protozoários da família Trypanosomatidae, do gênero Leishmania e podem-se apresentar clinicamente na forma visceral, cutânea ou cutâneo mucosa. São transmitidas pela picada da fêmea de insetos flebotomíneos conhecidos como sandfly em língua inglesa e mosquito palha no Brasil, sendo os do gênero Lutzomya os principais transmissores nas Américas. ${ }^{1,4}$

Calazar ou leishmaniose visceral (LV) é causada por espécies do complexo donovani. Estudos genéticos apontam similaridade entre as espécies chagasi e infantum, o que as caracterizaria como uma única espécie, denominada, por antiguidade, Leishmania infantum. ${ }^{1,5}$ A doença é descrita em 88 países e, destes, 76 são de baixa renda, incluindo os 13 mais pobres do mundo. Por isso, é uma das endemias prioritárias da Organização Mundial de Saúde (OMS), que estima a ocorrência de 300.000 a 400.000 casos novos a cada ano em todo o mundo. ${ }^{2}$ Dos casos novos, $90 \%$ ocorrem em 6 países: Índia, Bangladesh, Etiópia, Sudão, Sudão Sul e Brasil. ${ }^{2}$
Nas Américas, o calazar é descrito em 12 países, desde o México até a Argentina, sendo o Brasil responsável por $90 \%$ dos casos. ${ }^{6,7}$

No Brasil, foram registrados 35.228 casos de LV no período entre 2003 e 2012, com maior incidência nas regiões Norte, Nordeste e Centro-Oeste, seguindo-se a região Sudeste. ${ }^{10}$ Doença predominante até a década de 1990 nos estados da Região Nordeste e no estado de Minas Gerais, atualmente 23 Unidades Federadas registram casos de LV, o que caracteriza clara expansão territorial, com acentuação do índice de incidência nos estados das Regiões Norte e Centro-Oeste. Os maiores focos se encontram em Tocantins, Maranhão, Mato Grosso do Sul, Piauí, Ceará e Roraima, mas a doença é registrada em outros estados, inclusive Rio de Janeiro. ${ }^{3,7,10,12,14,15}$

A expansão das cidades e a urbanização dos países emergentes, como o Brasil, vêm causando uma modificação dos padrões epidemiológicos da $\mathrm{LV}$, com a ocorrência de casos na periferia ou mesmo nos centros urbanos. ${ }^{2,3,7}$ Acrescenta-se a isso, a sobreposição de áreas de ocorrência de LV e HIV, que propiciou o surgimento de nova entidade clínica, a coinfecção HIV/LV, em

Afiliação dos autores: Universidade Severino Sombra, Pró-Reitoria de Ciências da Saúde e Humanas, Curso de Enfermagem, Vassouras-RJ, Brasil

*Endereço para correspondência: Universidade Severino Sombra, Av. Exped. Oswaldo de Almeida Ramos, 280 - Centro - Vassouras, RJ - CEP 27700-000. E-mail: binhohb@hotmail.com 
que se observa o agravamento das duas enfermidades. Com isso, o calazar nas Américas, antes uma zoonose predominantemente rural e mais comum em crianças, acomete atualmente também a população urbana e, com frequência, adultos jovens e do sexo masculino. ${ }^{15,7}$

No estado do Rio de Janeiro, o calazar era doença desconhecida até 1977, quando foi descrito o primeiro caso na capital do estado. ${ }^{11}$ Desde então, a doença vem sendo identificada em vários municípios, registrandose 87 casos no município de Rio de Janeiro até 2006. ${ }^{12}$ Concomitantemente, neste município, observou-se elevada taxa de infecção em canídeos em bairros onde se registraram casos da doença. ${ }^{13}$ Mais recentemente, pacientes com LV vêm sendo diagnosticados em outros municípios do estado. Assim, no município de Barra Mansa, entre novembro de 2010 e setembro de 2013 registraram-se nove casos de $\mathrm{LV}^{14}$ e, em 2011, um caso autóctone foi identificado no Município de Volta Redonda. ${ }^{15}$ Ainda em 2011, trabalho realizado por Carvalho no município de Vassouras identificou cães infectados por leishmania, ${ }^{16} \mathrm{o}$ que traz a possibilidade de a infecção humana poder existir nesse município.

A transmissão da doença se dá pela picada da fêmea de Lutzomyia Longipalpis, flebotomíneo popularmente conhecido como mosquito palha ou birigui. A transmissão não se dá de pessoas para pessoas ou de animais para pessoas, apenas pela picada do mosquito contaminado, tendo o cão doméstico (Canis familiaris) como principal reservatório da doença tanto em áreas urbanas e rurais. ${ }^{1,2,4}$

Na natureza silvestre a raposa (Dusycion vetulus) e os marsupiais Didelphidae são os principais reservatórios da LV. O habito de manter os cães domésticos dentro de casa aumentam as possibilidades de infecção, assim como a construção de galinheiros perto das casas, pois estes são atraentes para as raposas. ${ }^{1}$

O mosquito palha não voa por mais de 50 metros do seu raio de origem, por isso a maioria da contaminação se dá no peridomicílio, ressaltando que a maioria dos infectados não desenvolve a doença, sendo de 18:1 a razão de aparecimento da doença, e geralmente com sintomas subclínicos, que podem ser confundidos com outras enfermidades. ${ }^{1,4}$

LV é de evolução lenta e com sinais clínicos que incluem: adinamia, hepatoesplenomegalia, pancitopenia, emagrecimento, perda de apetite, febre intermitente, onicose, fraqueza. O período de incubação da LV pode variar de 10 dias a 24 meses após a picada por mosquito infectado, sendo mais comum entre 2 a 4 meses. ${ }^{1,4}$

Considerando a gravidade da doença e a ocorrência de casos de LV em municípios vizinhos a Vassouras, bem como a constatação de cães infectados em locais deste município, realizou-se esta pesquisa de campo para identificar pessoas com possível infecção por Leishmania chagasi, além de orientar e educar sobre $\mathrm{LV}$ e os benefícios de seu diagnóstico precoce.

\section{Objetivo}

Esta pesquisa teve o objetivo de identificar pessoas com possível infecção por Leishmania chagasi no município de Vassouras, além de procurar, com o contato com a população em risco, esclarecer os moradores sobre LV e enfatizar os benefícios de diagnóstico precoce do calazar e da educação em saúde.

\section{Metodologia}

Foi realizado um estudo transversal baseado nas informações colhidas da pesquisa "Ações de Vigilância e Controle de Leishmaniose Tegumentar Americana e Leishmaniose Visceral no Município de Vassouras - RJ Brasil", , a qual era focada em tratar da leishmania em animais, mais especificamente em cães do município de Vassouras/RJ e repassado para a vigilância sanitária deste mesmo município.

De acordo com a vigilância sanitária desta cidade, foram encontrados dois cães sorologicamente positivos para calazar, entre sessenta cães com amostras analisadas nos bairros do Ipiranga e Bacia de Pedra, sendo um animal positivo em cada bairro. Estes locais se encontram às margens do rio Paraíba do Sul, por toda extensão do qual existe mata nativa, propiciando o desenvolvimento do flebotomíneo.

Com as informações acima, assim como o endereço onde viviam esses cães, foram colhidas amostra de sangue venoso da população que convivia com os animais em um raio de 100 metros, totalizando 17 amostras. Para coleta deste material foram utilizadas seringas de $5 \mathrm{ml}$, agulha de calibres adequados a cada situação e tubos para armazenamento.

Todo material usado era estéril, descartável e foi disponibilizado pela vigilância sanitária do município de Vassouras. Após a coleta, o sangue foi processado em centrífuga apropriada, no laboratório de histologia da Universidade Severino Sombra, e o soro enviado para análise no Laboratório Central de Saúde Pública Noel Nutels através da vigilância sanitária, e notificado ao Ministério da Saúde. Foi realizada a pesquisa de anticorpos contra o protozoário no soro, processado pelo método de ELISA (Enzyme-Linked Immunosorbent Assay).

Os bairros avaliados totalizam uma população de aproximadamente 2.500 habitantes. Com a impossibilidade logística de coleta de amostra de sangue de toda população, foram selecionadosos pacientes que viviam com os cachorros identificados como positivos, bem como os moradores que se encontravam próximos destes animais, em distância não maior que 100 metros de raio do endereço de cada animal. $\mathrm{Na}$ área assim delimitada, vivem aproximadamente 48 pessoas, 
portanto as amostras coletadas representam $35 \%$ da população exposta à possível contaminação.

Esta pesquisa foi realizada de julho de 2013 até junho de 2014. Foi preenchida uma ficha com informações clínicas de cada paciente (Anexo I), assim como foi assinado o termo de consentimento (Anexo II, adultos; Anexo III, menores). O exame clínico foi realizado por um acadêmico do curso de medicina da Universidade Severino Sombra e caso houvesse necessidade o paciente seria encaminhado para o Hospital Universitário Sul Fluminense.

Tanto no estudo que formou a base para a presente pesquisa, como neste trabalho, foram utilizados panfletos para melhor informação da população em questão.

Esta pesquisa científica foi aprovada pelo Comitê de Ética para Pesquisa (CEP) da Universidade Severino Sombra sob o número 22856613.5.0000.5290.

\section{Resultados}

A presente pesquisa foi realizada no segundo semestre do ano de 2013 e primeiro semestre de 2014. Das 17 amostras colhidas e enviadas para análise, nenhuma demonstrou sorologia positiva. A população contribuinte para a pesquisa foi informada sobre o resultado deste teste.

\section{Discussão}

Trabalhos de análise investigativa têm grande importância uma vez que ao se transmitir os resultados dos testes diagnósticos à população participante, há a oportunidade para educação, esclarecimento e detecção de outras enfermidades que potencialmente são assemelhadas ao calazar.

O período de coleta das amostras neste trabalho respeitou o período de incubação da doença, tendo em vista o momento em que os cães foram detectados como positivos, permitindo que casos positivos em humanos, caso existissem, fossem detectados.

No contexto clínico, o resultado sorológico negativo torna improvável a hipótese de calazar, exceto se o paciente for portador de HIV ou outra imunodeficiência severa, o que não é o caso de nenhum dos pacientes avaliados por essa pesquisa. ${ }^{1}$

A importância do diagnóstico precoce da doença como forma de melhorar a resposta terapêutica também contribuiu para a idealização deste estudo, uma vez que um dos objetivos era tranquilizar a população dos bairros em questão, além de promover a educação sobre a doença, já que durante a coleta a população foi informada sobre a zoonose, métodos de contágio e controle.

É sabido que o calazar muitas das vezes pode ser assintomático ou oligossintomático, por isso a vigilância, educação e controle sistemático do vetor devem ser mantidos. ${ }^{1}$ Mesmo não havendo diagnóstico do protozoário no soro dos pacientes pesquisados, não se elimina o risco de que outras pessoas na população da área de risco possam estar infectadas.

A população pesquisada foi informada sobre os resultados sorológicos negativos, não só para tranquilizar, mas também como o auxílio ao diagnóstico e tratamento de doenças preexistentes que poderiam ser confundidas com o calazar, uma vez que alguns dos indivíduos testados apresentavam outras enfermidades.

No presente estudo foi comprovada a existência do flebotomíneo, a presença do cão diagnosticado originalmente com a doença, a falta de saneamento básico, desinformação da população a respeito da doença e falta de proteção nas casas para a entrada do mosquito, todos fatores de alto risco para contaminação.

Novos estudos e uma inclusão mais ampla da população devem ser elaborados para o controle efetivo da leishmaniose no município de Vassouras. Os cães que foram diagnosticados com calazar no estudo anterior sofreram eutanásia, como preconiza o Ministério da Saúde, mas é importante salientar que muitos cães passam por longos períodos assintomáticos, se mantendo como reservatório da doença, aumentando o risco de contaminação humana.

Ainda de acordo com o Ministério da Saúde foram confirmados dois casos de calazar em humanos na região do rio Paraíba do Sul, mais especificamente em Barra Mansa, município esse próximo a Vassouras e aos bairros pesquisados. ${ }^{3}$

Desde 1997 há trabalhos demonstrando o calazar como uma zoonose emergente no interior do país, e pouco tem sido feito como trabalho de controle e educação sobre essa importante zoonose. ${ }^{17}$ Desta maneira esse estudo abordou não só o diagnóstico, como a educação da população sobre a doença, e a detecção de condições propícias à infecção humana.

Em um município no interior de São Paulo, que sofre com um crescente número de casos de calazar, a população ainda possui dúvidas sobre a forma de transmissão, onde muitos pacientes acham que a urina, saliva e fezes do cão podem ser responsáveis pela forma de contaminação. ${ }^{18}$

Em Minas Gerais o calazar vem atingindo algumas cidades do interior desde o século passado e pouco tem sido feito para o controle desta doença. Vale lembrar que Minas Gerais é um dos estados que faz fronteira com o estado do Rio de Janeiro. ${ }^{19}$

Desde 1977 o Instituto Oswaldo Cruz, já mostrava a presença desta zoonose no estado do Rio de Janeiro, e desde então pouco tem sido feito para esclarecimento da população sobre as formas de contato, e como a população pode se prevenir desta terrível zoonose. ${ }^{20}$ Constata-se pelo presente estudo, que mais providências necessitam ser tomadas para minimizar o risco de 
contaminação de animais e humanos pela leishmania.

\section{Conclusão}

Tendo em vista o exposto neste trabalho, fica clara a importância deste estudo, mesmo não encontrando pessoas contaminadas, uma vez que é vital persistir no trabalho de conscientização e educação, sendo este fundamental para que o calazar não se torne uma epidemia no município de Vassouras. A ação da Vigilância Sanitária para o controle de cães e do vetor deve ser contínua, uma vez que assim o risco de transmissão e infecção caem significativamente. $\mathrm{O}$ trabalho epidemiológico de forma sistemática é forte aliado para controle eficaz desta importância zoonose.

\section{Declarações}

Os autores não possuem conflitos de interesse diretos ou indiretos. Esta pesquisa tem o apoio da Universidade Severino Sombra e da Vigilância Sanitária do Município de Vassouras/RJ.

\section{Referências}

1. Tavares W, Marinho LAC. Rotinas de Diagnóstico e Tratamento das Doenças Infecciosas e Parasitárias, 3ª Edição, 2012, Atheneu;p.695-700.

2. WHO. Leishmaniasis. Fact Sheet $\mathrm{n}^{\circ} 375$, february 2015. Disponível em: http://www.who.int/mediacentre/factsheets/fs375/en/. Acessado em: maio 2015

3. Brasil. Ministério da Saúde. Secretaria de Vigilância em Saúde. Manual de Vigilância e Controle da Leishmaniose Visceral. Brasília:Ministério da Saúde, 2003. 122 p. Disponível em: http://www.crmv-mt.org.br/index.php/ artigos?id=128. Acessado em: maio 2015.

4. Duarte MIS, Badaró RS. Leishmaniose visceral (Calazar). In: Focaccia R. Tratado de Infectologia. $4^{\mathrm{a}}$ ed. São Paulo:Atheneu, 2009. p. 1705-36.

5.Gontijo CM, Melo MN. Leishmaniose visceral no Brasil: quadro atual, desafios e perspectivas. RevBrasEpidemiol2004;7:338-49.

6. Rodrigues da Silva J. Leishmaniose visceral (Calazar). Tese para Cátedra de Clínica de Doenças Tropicais e Infectuosas, Faculdade Nacional de Medicina, Universidade do Brasil. Rio de Janeiro, 1957. 498 p.

7. Elkhoury ANSM. Vigilância e controle da leishmaniose visceral no Brasil. In: Consulta de Expertos OPS/OMS sobre Leishmaniasis Visceral enLas Américas. Brasília:OPS/OMS, 2006. P. 24-26.
8. Migone L. Um caso de kala-azar a Assuncion, Paraguay. Bull Soc Path Exot 1913;6:118-20.

9. Penna HA. Leishmaniose visceral no Brasil. Brasil Med1934;48:949-50.

10. Brasil. Ministério da Saúde. Secretaria de Vigilância em Saúde. Portal Saúde. Leishmaniose visceral. Disponível em: http://portalsaude.saude.gov. br/index.php?option $=$ com content $\&$ view $=$ article $\& i d=11022 \&$ Itemid $=668$. Acessado em: maio 2015.

11. Salazar MC, Pinto FC, Gouveia LR, Bacha PC, Salgueiro PF. Leishmaniose visceral (relato de um caso autóctone na cidade do Rio de Janeiro). Revista Médica1979;8:19.

12. Marzochi, MC, Fagundes A, Andrade MV, Souza MB, Madeira MF, Mouta-Confort E et al. Visceral leishmaniasis in Rio de Janeiro, Brazil: ecoepidemilogicalaspectsandcontrol. RevSocBrasMedTrop2009;42:570-80.

13. Marzochi MC, Coutinho SG, Souza WJ, Toledo LM, Grimaldi Júnior G, Momen H, Pacheco RS, Sabroza PC, Souza MA, Rangel FBF, Tramontano NC. Canine visceral leishmaniosis in Rio de Janeiro, Brazil. Clinical, parasitological, therapeuticalandepidemiologicalfindings (1977-1983). Mem Inst Oswaldo Cruz1985;80:349-57.

14. Pimentel MI, Alves E, Silva MH, Moza P, Almeida PM, Cunha C, Mello $\mathrm{C}$, Schubach A. High visceral leishmaniasismortality rate in Barra Mansa, a new área of visceral leishmaniasistransmission in theStateof Rio de Janeiro, Brazil. RevSocBrasMedTrop, 47(4):521-523, Jul-Aug, 2014.

15. Sangenis LHC, Lima SRA, Mello CX, Cardoso DT, Mello JN, Espírito Santo MCC, Tavares W. Expansion of visceral leishmaniasis in the state of Rio de Janeiro, Brazil: report of the first autochtonous case in the municipality of Volta Redonda and the difficulty of diagnosis. RvInstMedTrop São Paulo 2014;56:271-74.

16. Carvalho FCG. Ações de vigilância e controle de leishmaniose tegumentar americana e de leishmaniose visceral no município de Vassouras, RJ, Brasil. In: XII Encontro de Iniciação Cientifica ENIC, 2013. Vassoura:Editora Universidade Severino Sombra,2013.p.119.

17. Santa Rosa ICA, Oliveira ICS. Leishmaniose Visceral: breve revisãosobre uma zoonose reemergente. Clínica Veterinária 1997; 2(11): 24-28.

18. Viol MA, Matos LVS, Aquino MCC, Alves IP, Bregadioli T, Oliveira BCM, Perri SHV, Bresciani KDS. Avaliação do grau de conhecimento sobre leishmaniose e toxoplasmose em moradores do município de Araçatuba, SP.VetZootec 2014:21(2): 309-13. Disponível em: http://www.fmvZ.unesp. br/rvz/index.php/rvz/article/view/667. Acessado em: maio 2015.

19. Silva MR, Santa Rosa ICA. Levantamento de leishmaniose visceral canina em Bom Sucesso, Minas Gerais. Acta ScientVet2005;33:69-74.

20. Marzochi MC, Coutinho SG, Souza WJ, Toledo LM, Grimaldi Júnior G, Momen H, Pacheco RS, Sabroza PC, Souza MA, Rangel FBF, Tramontano NC.Canine visceral leishmaniosis in Rio deJaneiro, Brazil. Clinical, paras itological,therapeuticalandepidemiologicalfindings (1977-1983). MemInst Oswaldo Cruz1985;80:349-57. 


\section{Anexo I \\ CENTRO DE VIGILÂNCIA EM SAÚDE - SMS DE VASSOURAS - RJ \\ AÇÕES DE VIGILÃNCIA E CONTROLE DE AGRAVOS POR ANIMAIS \\ LEVANTAMENTO SORO-EPIDEMIOLÓGICO DE LEISHMANIOSES EM PESSOAS}

Data de coleta: / / Zona: ( ) Rural ( ) Urbana Coord. Geográfica

Tipo de Área: ( )encosta ( )baixada ( )elevada ( )arborizada ( )mata ao redor ( )desmatada

IDENTIFICAÇÃO:

Paciente:

Tel:

Endereço:

$\mathrm{N}^{\circ}$ :

Bairro:

EXAME CLÍNICO E ANAMNESE:

Escore: ( )caquético ( )magro ( )normal ( )obeso Comportamento: ( )triste ( )ativo/normal ( )agitado

Temperatura: __ FR: ___ FC: ___ Turgor (desidrat): ( )ausente ( )leve ( )severa

Mucosas: ( )hipocorada ( )normocorada ( )ictérica ( )hiperêmica Perda de apetite: ( )sim ( )não

Linfonodos: ( )normais ( )alterados ( )quais estão

alterados:

Esplenomegalia: ( )sim ( )não Hepatomegalia: ( )sim ( )não Febre: ( )sim ( )não ( )alternante

Artralgia: ( )sim ( )não Edema de membros: ( )sim ( )não Lesões cutâneas? ( )sim ( )não quantas:

Quando começou?

Alopecia local: ( )sim ( )não Alopecia generalizada: ( )sim ( )não Descamação: ( )sim ( )não

Úlcera crostosa:( )sim ( )não Local das Lesões: ( )orelha ( )nariz ( )escroto ( )outros:

Dor à palpação renal: ( )sim ( )não Lesões oculares? ( )sim ( )não Tipo:

Quando começou?

Outros tipos de lesões: ___ Outras patologias atuais:

Distúrbios de coagulação na pele: ( )petéquias ( )equimoses Fezes e urina: ( )normais ( )alter adas

Histórico de epistaxe: ( )sim ( )não rinorragia:( )sim ( )não gengivorragia:( )sim ( )não

Tem assistência medica? ( )sim ( )não Frequência? ( )cada 6 meses ( )anual ( )só qd fica doente

Cartão de vacina em dia? ( )sim ( )não Quais?

\section{CARACTERÍSTICAS DA RESIDÊNCIA E DO PROPRIETÁRIO:}

Tipo de residência (observacional): ( ) pau a pique ( ) alvenaria ( )madeira ( ) outros:

Tipo de vegetação predominante ao redor da casa:

Presença de galinheiro: ( )sim ( )não Proprietário relata presença de mosquitos: ( )sim ( )não

Quantos cães na propriedade: outras espécies: ( )gatos ( )bovinos ( )equinos ( ) outros:

Presença de animais silvestres na área ou ao redor? ( )sim ( )não Quais: ( )capivara ( )gambá ( ) outros:

Paciente sabe o que são zoonoses?

Resposta:

Conhece doenças transmitidas do cão para o homem? ( )sim ( )não Quais:

Paciente informado sobre a Leishmaniose? ( ) sim ( ) não Paciente conhece o vetor? ( ) sim ( ) não

Já ouviu falar de algum morador da localidade com leishmaniose? ( )sim ( )não

Grau de escolaridade: ( )nunca estudou ( )fundam incompl ( )fundam completo ( )médio ( )superior

Faixa etária: ( )menor que 20 anos ( ) 20 a 30 anos ( ) 30 a 40 anos ( ) 40 a 60 anos ( )acima de 60 anos

Condição econômica (observacional): ( )baixa ( )média ( )alta 


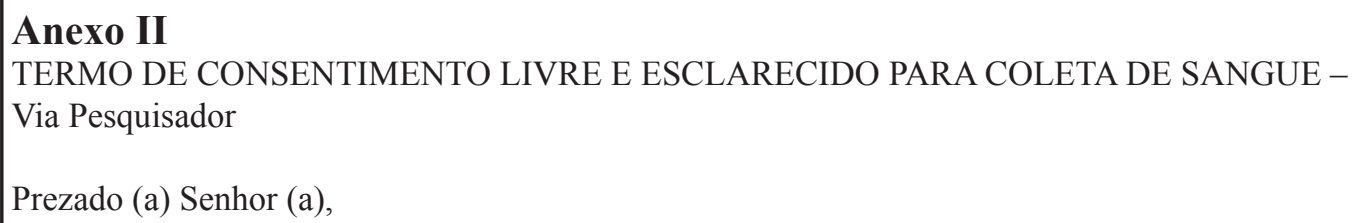

A operacionalização desta pesquisa ocorrerá nos bairros de Vassouras onde serão realizadas visitas domiciliares, aplicação de questionário contendo informações a respeito dos animais da residência e coleta de sangue das pessoas para realização de exame sorológico destes. Assim, contamos com a sua participação na entrevista. Os instrumentos de coleta utilizados são de caráter estritamente confidencial e a divulgação dos dados, descartados após analise, através da produção de texto ou apresentação em evento de caráter estritamente cientifico.

Após a entrevista, caso sinta necessidade, estaremos à disposição para discutir alguma questão que tenha deixado dúvidas. Existe o possível risco de constrangimento do participante em responder as questões. Salientamos a sua inteira liberdade de se recusar a participar ou se retirar da pesquisa em qualquer momento do andamento da mesma, sem penalização.

Atenciosamente, Flávia Clare Goulart de Carvalho,

Por esse instrumento, eu

autorizo a realização da pesquisa acima descrita. Afirmo que fui devidamente esclarecido quanto aos objetivos da pesquisa, o caráter confidencial e o destino dos dados coletados (os relatos gravados serão transcritos e os dados, depois de analisados serão descartados, podendo ser divulgados por meio de produção de texto cientifico ou de apresentação em evento de caráter cientifico). Bem como, o meu direito de não participação ou o meu afastamento a qualquer momento da pesquisa. Todos os dados referentes à pesquisa respeitarão o direito de não identificação.

Vassouras, de

de 2014

Assinatura

Para esclarecer quaisquer duvidas ou para encaminhar sugestões:

PESQUISADOR RESPONSÁVEL

Flavia Clare Goulart de Carvalho e-mail: flaviaclare@gmail.com

COMITE DE ETICA EM PESQUISA DA PMV COMITE DE ETICA EM PESQUISA DA USS. 


\title{
Anexo III
}

TERMO DE CONSENTIMENTO LIVRE E ESCLARECIDO PARA COLETA DE SANGUE DE MENORES DE 18 ANOS Via Pesquisador

Prezado (a) Senhor (a),

Você esta sendo convidado a participar do trabalho de pesquisa "Inquérito Epidemiológico de Leishmaniose Tegumentar e Visceral Humana no município de Vassouras - RJ" que tem por objetivo identificar pessoas soropositivos para Leishmaniose no município de Vassouras RJ. Alertando os moradores em relação à doença e orientando-os como deve ser feita a profilaxia para evitar esta zoonose.

Este trabalho faz parte do estudo de campo pela professora Flávia Clare Goulart de Carvalho na Universidade Severino Sombra. Este estudo tem como justificativa a importância dos resultados para a comunidade científica e sociedade civil através da identificação des pessoas soropositivos e esclarecimento da população quanto essa importante zoonose, evitando assim, o aumento desta enfermidade nessa e em outras regiões.

A operacionalização desta pesquisa ocorrerá nos bairros de Vassouras onde serão realizadas visitas domiciliares, aplicação de questionário contendo informações a respeito dos animais da residência e coleta de sangue das pessoas para realização de exame sorológico destes. Assim, contamos com a sua participação na entrevista. Os instrumentos de coleta utilizados são de caráter estritamente confidencial e a divulgação dos dados, descartados após analise, através da produção de texto ou apresentação em evento de caráter estritamente cientifico.

Após a entrevista, caso sinta necessidade, estaremos à disposição para discutir alguma questão que tenha deixado dúvidas. Existe o possível risco de constrangimento do participante em responder as questões. Salientamos a sua inteira liberdade de se recusar a participar ou se retirar da pesquisa em qualquer momento do andamento da mesma, sem penalização.

Atenciosamente, Flávia Clare Goulart de Carvalho,

Por esse instrumento, eu CI autorizo a realização da pesquisa acima descrita. Autorizo a coleta de sangue do menor

o qual sou responsável. Afirmo que fui devidamente esclarecido quanto aos objetivos da pesquisa, o caráter confidencial e o destino dos dados coletados (os relatos gravados serão transcritos e os dados, depois de analisados serão descartados, podendo ser divulgados por meio de produção de texto cientifico ou de apresentação em evento de caráter cientifico). Bem como, o meu direito de não participação ou o meu afastamento a qualquer momento da pesquisa. Todos os dados referentes à pesquisa respeitarão o direito de não identificação.

Vassouras, de

de 2014

\author{
Assinatura \\ Para esclarecer quaisquer duvidas ou para encaminhar sugestões: \\ PESQUISADOR RESPONSÁVEL \\ Flavia Clare Goulart de Carvalho e-mail: flaviaclare@gmail.com \\ COMITE DE ETICA EM PESQUISA DA PMV COMITE DE ETICA EM PESQUISA DA USS.
}

